
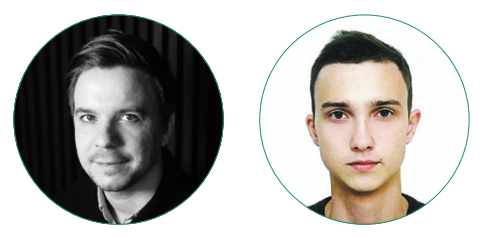

Н. И. Руденко, Р. В. Малюшкин

\title{
МОБИЛЬНОСТЬ И ГЕНДЕРНЫЕ РАЗЛИЧИЯ РОССИЙСКИХ ИНЖЕНЕРОВ ПО МАТЕРИАЛАМ СОЦИАЛЬНОЙ СЕТИ “ВКОНТАКТЕ»
}

\section{Правильная ссылка на статью:}

Руденко Н.И., Малюшкин Р.В. Мобильность и гендерные различия российских инженеров по материалам социальной сети "ВКонтакте" // Мониторинг общественного мнения: экономические и социальные перемены. 2021. № 3. С. 88-104. https://doi.org/10.14515/ monitoring.2021.3.1723.

\section{For citation:}

Rudenko N. I., Maliushkin R. V. (2021) Mobility and Gender Differences of Russian Engineers Based on the Materials of the Social Network VKontakte. Monitoring of Public Opinion: Economic and Social Changes. No. 3. P. 88-104. https://doi.org/10.14515/monitoring. 2021.3.1723. (In Russ.) 
МОБИЛЬНОСТЬ И ГЕНДЕРНЫЕ РАЗЛИЧИЯ РОССИЙСКИХ ИНЖЕНЕРОВ ПО МАТЕРИАЛАМ СОЦИАЛЬНОЙ СЕТИ "ВКОНТАКТЕ"

РУДЕНКО Николай Иванович - кандидат социологических наук, научный сотрудник, Центр исследований науки и технологий, Европейский университет в Санкт-Петербурге, Санкт-Петербург, Россия

E-MAIL: diogenstyx@gmail.com

http://orcid.org/0000-0001-9511-3881

МАЛЮШКИН Роман Вячеславович независимый исследователь, СанктПетербург, Россия

E-MAIL: malyushkinr@gmail.com

http://orcid.org/0000-0003-1659-925X

Аннотация. В статье на основе данных из социальной сети "ВКонтакте» (более 36 тыс. профилей) анализируются географическая и образовательная мобильность, а также гендерный разрыв (как в учебе, так и на рабочем месте) среди российских инженеров. Мобильность (в географическом и образовательном плане) и гендерные различия рассматриваются как важные элементы инновационного развития: первая предполагает возможность мобильности навыков, людей, знаний из одной отрасли в другую и из одной локации в другую, вторые - доступ к получению образования и работы в новых инновационных сферах для людей разного гендера. В ходе анализа выявлено, что российские инженеры, как правило, не мобильны: большинство остаются работать в том же городе, где получали первое образование; исключение составляют Москва и Санкт-Петербург,
MOBILITY AND GENDER DIFFERENCES OF RUSSIAN ENGINEERS BASED ON THE MATERIALS OF THE SOCIAL NETWORK VKONTAKTE

Nikolay I. RUDENKO ${ }^{1}$ - Cand. Sci. (Soc.), Research Fellow, Science and Technology Studies Center

E-MAIL: diogenstyx@gmail.com

http://orcid.org/0000-0001-9511-3881

Roman V. MALIUSHKIN ${ }^{2}$ - Independent researcher

E-MAIL: malyushkinr@gmail.com

http://orcid.org/0000-0003-1659-925X

\footnotetext{
${ }^{1}$ European University at St. Petersburg,

Saint Petersburg, Russia

2 Saint Petersburg, Russia
}

Abstract. This article is based on data from the social network VKontakte (more than thirty-six thousand profiles) and analyzes geographic and within education mobility as well as the gender gap among Russian engineers. Mobility (geographical and educational) and gender differences are considered as important elements of innovative development: the first assumes the mobility of skills, people, and knowledge from one industry to another and from one place to another; the second assumes access to education and work in new innovative areas for people of different genders. Our analysis revealed that Russian engineers, as a rule, are immobile (the majority work in the same city where they received their education). The exception is Moscow and St. Petersburg where more engineers work and live than have studied. Although the evidence suggests that the engineering profession is dominated 
где работает и живет больше инженеров, чем училось. Данные говорят о том, что в инженерной профессии преобладают мужчины. В то же время выявлены сферы, где женщин численно больше: это микробиология, химия, экология, картография. Обнаружено, что в России усиливается отток женщин из инженерного образования по мере роста ступеней образования. Женщины-инженеры, несмотря на полученное образование, чаще работают на подчиненных нетехнических работах и выполняют бюрократические задачи.

Ключевые слова: инженеры, ВКонтакте, гендерные различия, мобильность, инновационное развитие

Благодарность. Исследование выполнено при финансовой поддержке РФФИ в рамках научного проекта № 20-01100690 А. "Инженерная карьера в современной России: профессиональные, организационные и институциональные трансформации". by men, we identified specialties where women are numerically more: microbiology, chemistry, ecology, and cartography. We found that in Russia the outflow of women from engineering education is increasing as its levels grow. Female engineers are more likely to work in subordinate non-technical jobs and perform bureaucratic tasks.

Keywords: engineers, VKontakte, gender gap, mobility, innovative development

Acknowledgments. The reported study was funded by PFBR, project number No. 20-011-00690 A “Engineering Career in Modern Russia: Professional, Organizational and Institutional Transformations".

\section{Введение}

Россия остается одной из ведущих стран по числу выпускаемых из вузов инженеров $^{1}$. Однако для устойчивого развития инновационной экономики требуются не столько количественные, сколько качественные показатели. Министерство образования интересуется вопросом, как поднять качество инженерного образования в России [Мансуров, Юрченко, 2016]. Предполагается, что для этого нужно обновить содержание инженерного образования, приспособить его для рыночной ситуации и в целом поднять престиж профессии ${ }^{2}$. С нашей точки зрения, помимо этих важных задач есть и две других, которые также характеризуют инновацион-

\footnotetext{
${ }_{1}$ McCarthy A. The Countries With the Most Engineering Graduates: Infographic //Forbes. 2015. January 9. URL: https:// www.forbes.com/sites/niallmccarthy/2015/06/09/the-countries-with-the-most-engineering-graduates-infographic/ \#1e76b3fe667d (дата обращения: 28.06.2021).

2 Статистика: Высшее образование // Министерство высшего образования и науки РФ. 2020. URL: https://minobrnauki. gov.ru/action/stat/highed/ (дата обращения: 28.06.2021).
} 
ный потенциал российских инженеров. Это решение проблем гендерного разрыва в профессии и мобильности инженеров ${ }^{3}$.

Под гендерным разрывом мы понимаем паттерны ${ }^{4}$ того, как в образовательном и профессиональном треках развития женщины и мужчины распределяются по специальностям, образовательным ступеням, должностям и позициям на рабочем месте. Российские и зарубежные исследователи отмечают, что в инженерных профессиях наблюдается перекос в выборе профессии среди мужчин и женщин: женщины менее охотно идут работать инженерами, они занимают менее престижные позиции, чем мужчины, получая меньшую зарплату [Абрамов, 2016; Варшавская, Котырло, 2019]. Некоторые из этих выводов подкрепляются образовательной статистикой ${ }^{5}$. СМИ в России также активно пишут о наличии гендерного разрыва ${ }^{6}$. Полагаем, что подобные паттерны ограничивают возможность довольно широкого слоя российского общества заниматься определенными видами деятельности, занимать престижные позиции, иметь хорошие зарплаты и участвовать и инновационном развитии в будущем. Следовательно, экономика, нуждающаяся в инновациях, лишается многочисленных инженерных кадров, нужных для нее ${ }^{7}$. Как отмечает Е. Колесникова, “открытость доступа в [инженерную] профессию важна с точки зрения равенства возможностей для включения в нее наиболее перспективных, многообещающих „новичков“" [Колесникова, 2018].

Второй показатель - мобильность инженеров - это паттерны перемещения в географическом, образовательном, карьерном планах. Капиталистическая экономика ориентируется на новые появляющиеся рынки и, следовательно, предполагает постоянную подвижность. Как показывают исследования, компании, которые занимаются инновациями, выигрывают от дополнительной гибкости и подвижности в навыках, кадрах, проектах [Herrera, Muñoz-Doyague, Nieto, 2010; Kaiser, Kongsted, Rønde, 2015]. Таким образом, мобильность является важным фактором развития инноваций и технического развития. В отличие от гендерной тематики о мобильности российских инженеров написано довольно мало - прежде всего из-за нехватки данных.

\footnotetext{
${ }^{3}$ В данной статье мы будем рассматривать бо́льшую образовательную и географическую мобильности и отсутствие гендерных различий в выборе специализации и мест работы как позитивно коррелирующую с бо́льшей инновационностью [Herrera, Muñoz-Doyague, Nieto, 2010]. Мы отдаем себе отчет, что географическая и образовательная иммобильность может быть позитивным социальным явлением, к примеру, позволяющим инженерам сокращать риски потери работы в меняющейся социально-экономической обстановке. Однако для целей инновационной экономики ригидность экспертизы, рабочей силы и существующие гендерные границы служат, скорее, тормозом развития.

4 Под паттерном мы понимаем в общем смысле повторяющуюся и зачастую закономерную структуру отношений. Так, мы говорим о паттернах гендерных различий и паттернах мобильности, имея в виду повторяющиеся коллективные формы выбора специальности или выбора места работы и городов проживания.

5 Статистика: Высшее образование // Министерство высшего образования и науки РФ. 2020. URL: https://minobrnauki. gov.ru/action/stat/highed/ (дата обращения: 28.06.2021).

6 Необходимость сокращения ген дерных разрывов обсудили на Всемирной женской ассамблее. Известия. 2019. 25 марта. URL: https://iz.ru/860515/2019-03-25/neobkhodimost-sokrashcheniia-gendernykh-razryvov-obsudili-navsemirnoi-zhenskoi-assamblee (дата обращения: 28.06.2021); [TACC, 2017] Научно-технологическая сфера США и Европы избавляется от гендерных стереотипов //TACC. 2017. 28 ноября. URL: https://tass.ru/plus-one/4765527 (дата обращения: 28.06.2021).

7 Стратегия инновационного развития РФ до 2020 года. М. : Аналитический центр при Правительстве РФ. 2014. URL: https://ac.gov.ru/files/attachment/4843.pdf (дата обращения: 28.06.2021).
} 
В нашей статье рассматриваются два аспекта инновационного развития инженеров -гендерное распределение и мобильность. При этом мы опираемся на данные, которые еще не были использованы в полной мере для анализа инженерной профессии в России,- - именно материалы социальной сети "ВКонтакте».

\section{Гендер и мобильность в исследовательской литературе}

Гендерный вопрос в инженерной профессии

В 2000-е годы в социологии появляется ряд работ, где подробно анализируется гендерный вопрос в инженерной профессии. Исследователи отмечают высокую долю российских женщин в инженерной профессии по сравнению с другими странами (40\%-60\% в РФ по сравнению с 10-20\%, например, в США). Упоминается, что в СССР власти особо подчеркивали важность женщин-инженеров для экономики. Р. Абрамов говорит о феминизации профессии в советский период, хотя и отмечает, что женщины в основном работали, скорее, как технический и поддерживающий персонал. В то же время он утверждает, что фундаментальной характеристикой профессии сегодняшнего дня является маскулинность [Абрамов, 2016]. Мы видим гораздо меньше женщин, обучающихся инженерным специальностям на уровне магистратуры и аспирантуры. Впрочем, отдельные инженерные специальности (например, биология, химия и картография) остаются "женскими" [Kovaleva, 1999].

Что касается доли женщин, приходящих после окончания вузов на инженерные рабочие места, то она устойчиво падает. Так, Е. Колесникова отмечает, что готовность работать по специальности выражают 63,5\% юношей и только 44,1\% девушек [Колесникова, 2018]. Согласно материалам Российского статистического ежегодника, в инженерных видах экономической деятельности доля женщин колеблется от $13 \%$ до 33\%. На рабочем месте женщины продолжают играть роль поддерживающего персонала, занимающегося скорее бюрократическими, чем техническими задачами, при этом их средняя зарплата обычно ниже, чем у мужчин [Варшавская, Котырло, 2019].

Западные исследователи до сих пор отмечают высокий интерес женщин в России к инженерному делу и математике, что особенно заметно на фоне сравнения с другими странами ${ }^{8}$. Однако общие тенденции в гендерном дисбалансе схожи. Э. Блоссер, говоря о ситуации в США, отмечает, что в среднем только $19 \%$ заканчивающих бакалавриат по инженерным специальностям - женщины [Blosser, 2017]. Проблема сегрегации проявляется не только в том, что женщины не идут на инженерные специальности, но и в том, что они постепенно теряют мотивацию обучаться этим специальностям в дальнейшем. Об исключении женщин из инженерного образования говорит и другая американская исследовательница Э. Слэйтон [Slaton, 2015]. При этом в Штатах, как и в России, существуют отдельные более "женские" специальности, связанные, например, с биотехнологиями и химическими технологиями, в то время как электроэнергетика, машиностроение, электрическая инженерия, информационные технологии, строительство остаются по преимуществу мужскими [Kovaleva, 1999; Blosser, 2017]. У. Фолкнер на примере работы компании, оказывающей услуги в сфере цифровых технологий, отмечает

\footnotetext{
8 Bullock C. Why is Russia so Good at Encouraging Women into Tech? //BBC News. 2017. April 21. URL: https://www. bbc.com/news/business-39579321 (дата обращения: 28.06.2021).
} 
гендерное разделение в инженерной деятельности, где математические или технические задачи реализуются преимущественно мужчинами, а социальные и коммуникативные - женщинами. Это вошло в литературу как феномен дуализма в инженерной профессии [Faulkner, 2000]. Схожую тенденцию мы наблюдаем и в Европе: женщины в странах-членах Евросоюза недопредставлены в сферах математики, компьютерных наук, в инженерном деле и архитектуре [Sagebiel, Dahmen, 2006].

Таким образом, можно сделать следующие выводы по результатам анализа литературы: 1) в инженерной профессии женщин гораздо меньше, чем мужчин (в среднем их доля - 25\%-30\%); 2) существует сегрегация в образовании, которая заставляет их бросить образование и блокирует образовательный трек; 3) меньше женщин работает на инженерных специальностях; 4) на рабочем месте женщины зачастую выполняют более рутинные обязательности, зачастую не связанные напрямую с технической деятельностью.

\section{Мобильность инженеров}

Другой важный аспект исследования связан с мобильностью. Здесь исследовательских работ ощутимо меньше. Изучение представлений о будущем студентовинженеров показывает, что основным желаемым местом работы для будущих инженеров остаются большие государственные предприятия: молодые люди полагают, что работа здесь даст им стабильность и социальные бонусы [Варшавская, Котырло, 2019]. Материалы другого исследования, где рассматривается положение российских инженеров на нескольких уральских заводах, показывает, что большинство специалистов не помышляют о переходе в другие организации и видят свои профессиональные перспективы только внутри тех компаний, где уже работают [Козина, Виноградова, 2016]. Таким образом, инженеры представляют свой карьерный путь как стабильный проект с возможностью расти внутри предприятия. Литература фиксирует тенденцию к иммобильности инженеров.

Рассмотренные работы в основном опираются на данные статистики либо основаны на интервью. Насколько нам известно, к данным соцсетей исследователи еще не обращались, хотя, на наш взгляд, подобные данные могут быть источником ценной информации и о гендерном разрыве, и о паттернах географической мобильности в инженерной профессии. Они могут уточнить или триангулировать статистические данные, продемонстрировать распространенность трендов. Мы хотим предложить этот ход и, опираясь на материалы более 30 тысяч профилей во "ВКонтакте", ответить на три вопроса, которые уже ставились в литературе, но на которые можно получить более полный ответ.

1) Каков половозрастной состав современных российских инженеров? Где они учатся и где проживают?

2) Что из себя представляет географическая и образовательная мобильность инженеров? Откуда и куда эти люди переезжают? Каковы их образовательные треки $^{9}$

3) Какие гендерные различия мы можем найти среди современных российских инженеров? Как эти различия проявляются в образовании и на рабочих местах?

\footnotetext{
9 Вопрос карьерных траекторий мы оставляем для других статей, поскольку он нуждается в дополнительном анализе.
} 


\section{Методы и данные}

Основным источником данных в нашем исследовании была выбрана социальная сеть "ВКонтакте" - одна из самых посещаемых платформ в России (согласно анализу интернет-трафика за май 2019 г., вторая после поисковика Google). Среднемесячная аудитория “ВКонтакте» - 198 млн человек (май 2019).

"ВКонтакте" позволяет отправлять личные сообщения, создавать новости и делиться ими, взаимодействовать в онлайн-сообществах. Ключевой элемент платформы - это личная страница, содержащая изображение пользователя, информацию о нем, предпочтения и т. д. В информации о владельце аккаунта также есть и социодемографические данные (возраст, гендер, образование, место работы), которые могут быть ценными для анализа паттернов, о которых мы говорили выше. Социальная сеть предоставляет свободный доступ к указанным материалам ${ }^{10}$.

Мы собирали публичные данные пользователей, которые в графе "должность" указывали "инженер" (включая и составные слова, где “инженер" - одна из частей слова типа "инженер-конструктор" и проч.) ${ }^{11}$. На момент сбора данных (май 2019) таких профилей оказалось 145910. Затем из этого количества профилей мы выбрали те, в которых была заполнена информация о возрасте, образовании, месте работы и т. д. Их оказалось 36978. Именно на них мы проводили основной анализ, и именно они являются нашей выборкой.

Чтобы подтвердить, что данные, с которыми мы работаем, отражают именно особенности инженерной профессии, а не являются артефактом социальной сети "ВКонтакте", мы сравнили их с половозрастным распределениями из проекта «Виртуальное население России" (BHP, http://webcensus.ru/). В соответствии с данными этого сайта в большинстве российских регионов доли мужчин и женщин, пользующихся сетью «ВКонтакте», примерно равны. В нашей выборке доля мужчин почти в два раза выше (см. диаграмму на рис. 1). Другое отличие - возраст. Анализ ВНР говорит, что большинство пользователей ВК - молодые люди в возрасте 18-29 лет (их около половины), 20\% приходится на 30-40-летних и 16\% - на тех, кому 40-60 лет. Наши данные также не соответствуют этому распределению. Диаграмма на рис. 1 показывает, что средний возраст "инженеров" - 33-35 лет, а тех, кому 40, столько же, сколько и тех, кому 25. Данные различия показывают, что мы работаем с отдельной группой, обладающей своими социодемографическими характеристиками.

При этом мы не утверждаем, что наша выборка является точным отражением всех российских инженеров офлайн. Мы понимаем, что она нерепрезентативна. Наши выводы распространяются лишь на тех 36978 инженеров, с которыми мы работали. Но выборка, как мы показали, отличается в целом от людей, которые просто пользуются «ВКонтакте».

\footnotetext{
${ }^{10}$ Мы пользовались открытой API-инфраструктурой и собирали только те сведения, которые были публично открыты в профиле и не нарушали приватность пользователей.

${ }^{11}$ В выборку попали те, кто считал, что работает инженером по своей должности. В нее не попали люди, которые только учатся на инженера, и те, чья должность не звучит как "инженер" (хотя эти люди могут решать инженерные задачи). На наш взгляд, фильтр самоопределения позволяет охватить довольно широкое и неопределенное понятие инженера, которое не только претерпело инфляцию в позднесоветский период, но и увеличило свой объем после прихода рыночной экономики.
} 
Во Вконтакте существуют ненастоящие (фейковые) и брошенные аккаунты. Чтобы справиться с этой проблемой, мы выбирали аккаунты, в которых заполнены данные о возрасте, месте работы, образовании и т. д. Разумеется, это не избавляет нас от проблемы ненастоящих аккаунтов как таковой, но мы работали с более чем 36 тысячами аккаунтов и полагаем, что по закону больших чисел количество искажений в данных должно уменьшаться, а закономерность - возрастать с увеличением количества единиц. Что касается брошенных аккаунтов, то, если информация в них валидная, это не мешало проведению нашего анализа.

В дальнейшем "валидность" нашей выборки мы также обосновываем путем триангуляции ее с выводами других исследователей, изучающих российских инженеров.

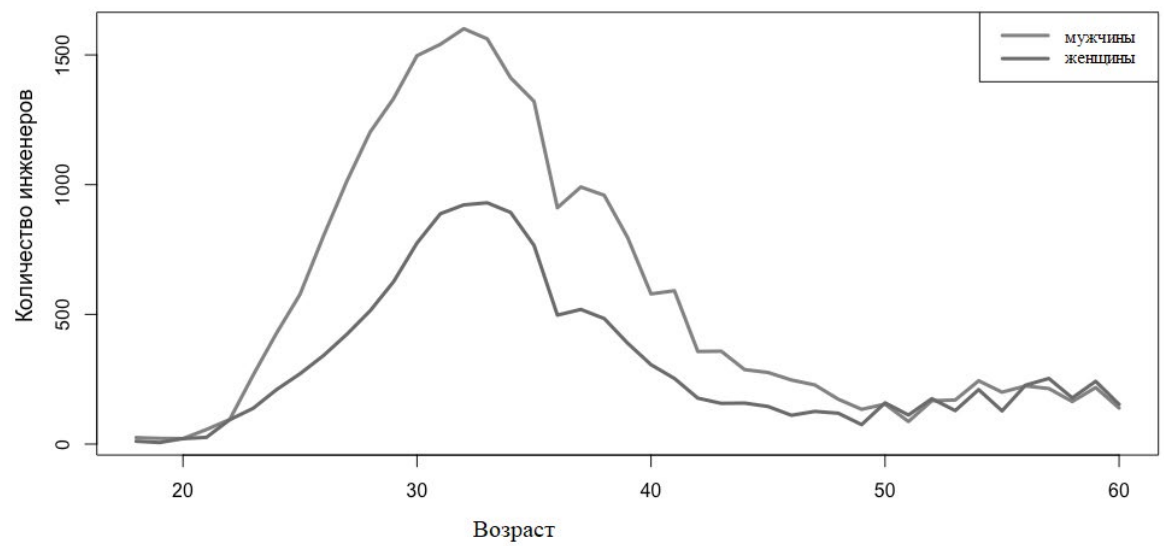

Рис. 1. Социодемографический анализ выборки российских инженеров “ВКонтакте» ${ }^{12}(N=36978)$

\section{Результаты}

Общая социодемография инженеров

Как видно из диаграммы на рисунке 1, в нашей выборке мода возраста пришлась на 33-35 лет. Несмотря на то, что аудитория "ВКонтакте» искажена в сторону более молодого возраста хотя бы из-за специфики сетевого контента, эти данные в целом соответствует утверждению, высказанному Е. Варшавской и ее коллегами: среди инженеров доля молодых людей (25-34 года) в полтора-два раза выше, чем среди представителей группы 55-64 лет [Варшавская, Котырло 2019].

Самый яркий, бросающийся в глаза тренд на диаграмме, следующий: в промежутке между 30 и 40 годами количество мужчин-инженеров не менее чем вдвое превышает количество женщин-инженеров. Рост числа мужчин на инженерных специальностях начинается с 22-23 лет (возраст начала работы по профессии) и уравнивается с объемом работающих инженеров-женщин только примерно к 50 годам. Даже с учетом искажений ВК этот тренд подтверждает выводы других

\footnotetext{
12 Всюду далее $N=36978$, кроме специально оговоренных случаев.
} 
авторов о том, что женщины меньше представлены в инженерных специальностях по сравнению с мужчинами.

Диаграмма на рисунке 2 показывает города обучения (первая учеба) и настоящего проживания инженеров ВК. Мы видим, что около 40 \% тех, кто попал в выборку, получили или получают первое образование в столицах - Москве и Санкт-Петербурге. В Екатеринбурге и Новосибирске обучаются совокупно еще $10 \%$. Остальные инженеры из нашей выборки учились в других городах (Нижний Новгород, Самара, Пермь и т.д.). В целом такое распределение кажется неудивительным, поскольку названные выше города - это технические, промышленные или научные центры России. При этом в большинстве из них есть свои вузы-монополисты. В Перми, например, это Пермский национальный исследовательский политехнический университет (там обучаются $60 \%$ инженеров из Перми). В ЕкатеринбургеУральский федеральный университет (54\% инженеров из Екатеринбурга), В Нижнем Новгороде - Нижегородский государственный технический университет (44\%). В Москве и Санкт-Петербурге таких образовательных монополистов нет.

Из диаграммы видно, что большинство представителей нашей выборки (86\%) остаются жить там, где получили первое образование. Это свидетельствует о иммобильности российских инженеров, о которой мы упомянули выше.

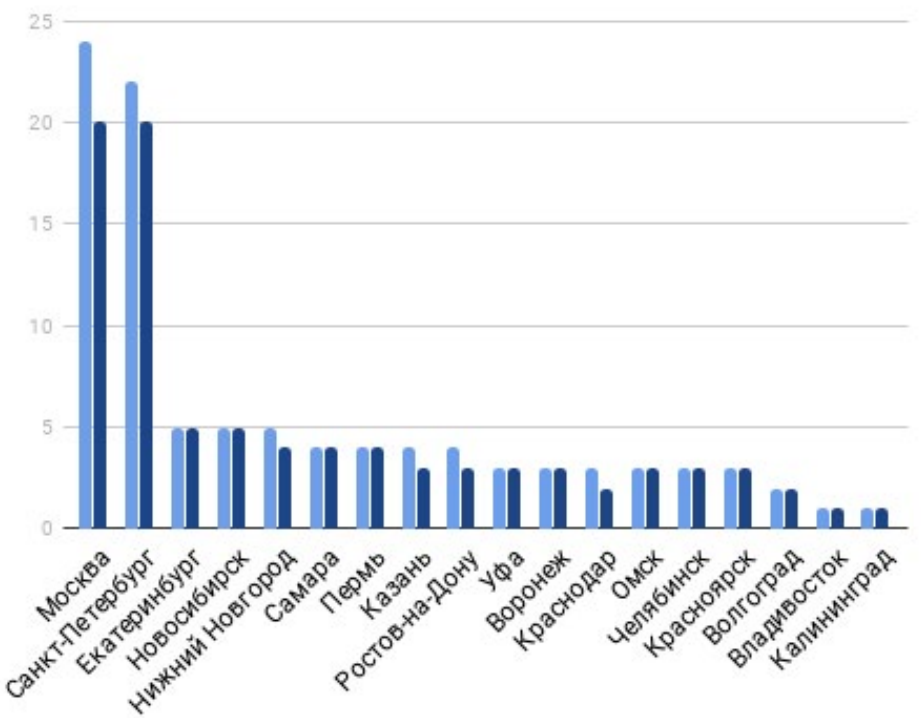

Рис. 2. Города первой учебы и города настоящего проживания

Социодемографический и географический анализ показывает, что в нашей выборке женщин в среднем меньше, чем мужчин, а в наиболее активном профессиональном возрасте (30-40 лет) их становится вдвое меньше. Это подтверждает существующие выводы в литературе.

Другой важный аспект - наглядная демонстрация того, что у Москвы и СанктПетербурга существует своеобразная, хотя ограниченная «монополия" на образова- 
ние и проживание инженеров: около 40 \% из них учатся в этих городах и около $45 \%$ проживают в настоящее время. Отдельные центры притяжения инженеров созданы в крупных промышленных городах или научно-технических центрах. Однако в целом в других крупных городах учатся не более 5 \% и меньше от общей выборки в каждом.

\section{Географическая и образовательная мобильность инженеров}

В данном разделе мы коснемся географической и образовательной мобильности. Как очевидно из диаграммы на рисунке 2, $86 \%$ инженеров из нашей выборки остаются жить и работать там, где получили свое первое высшее образование. Очевидно, что в России сложилась система географически распределенного спроса на инженерные кадры. Специальность предполагает прохождение производственной практики, и это затем может привести к предложению работы [Варшавская, Котырло, 2019]. Большую роль здесь играют вузы и даже отдельные преподаватели.

Два города, куда инженеры относительно массово приезжают после первой учебы,- - это Москва и Санкт-Петербург. Другие города России можно разделить на "притягивающие" и "отталкивающие". Так, интерес у работающих инженеров устойчиво вызывают такие города, как Нижний Новгород, Ростов-на-Дону, Краснодар, Казань. Главными городами-поставщиками инженеров в другие регионы являются Пермь, Омск, Уфа, Волгоград, Иркутск и т.д.

Попробуем разобраться, в чем причина. Посмотрим на рисунок 3, на котором представлена тепловая карта (или цветовая матрица).

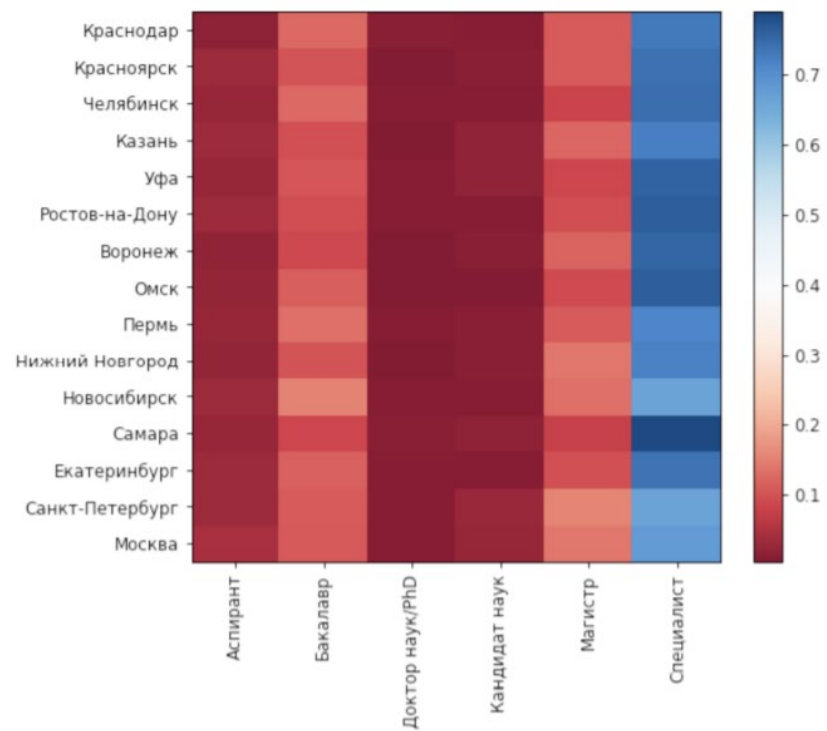

Рис. 3. Цветовая матрица городов и образовательных ступеней ${ }^{13}$

\footnotetext{
13 Чтобы прочитать карту, нужно обратить внимание на интенсивность цвета ячейки на пересечении двух значений статуса (ось X) и города (ось Y). Цвета и их значение представлены на легенде справа. Градация значений идет от темно-красного (самое низкое значение) до темно-синего (самое высокое). Чем более темно-красным окрашена ячейка, тем меньше показатель, чем более темно-синим - тем выше показатель. К примеру, в Новосибирске больше всего специалистов, поменьше - бакаларов, еще меньше магистров и аспирантов.
} 
Для Москвы очевидно нарастание долей магистров, аспирантов, кандидатов наук. Налицо связь географической и образовательной мобильности: инженеры едут в Москву продолжать учебу.

В Челябинске наоборот: специалистов и бакалавров много, а магистров и студентов более высоких ступеней - гораздо меньше. Такие города привлекательны с точки зрения рабочих мест, но не могут предоставить всем, кто готов повышать уровень своего образования, соответствующие их требованиям площадки. Тот же паттерн мы видим и в Уфе: количество инженеров уменьшается уже на стадии перехода от бакалавров к магистрам.

В Санкт-Петербурге и Перми цветовое распределение по образовательным ступеням представлено довольно равномерно (небольшое снижение только на уровне аспирантуры), а значит и причины отъезда из этих городов связаны с предложениями работы, а не с учебой.

Анализ показывает, что в контексте мобильности инженеров города можно поделить на четыре основных типа: 1) притягивающие хорошим образованием (Москва, Нижний Новгород, Воронеж); 2) притягивающие работой (Челябинск, Уфа); 3) отталкивающие уровнем образования (Самара, Челябинск), 4) отталкивающие отсутствием достойной работы (Пермь, Омск). При этом за пределами Москвы и Санкт-Петербурга мобильность инженеров не очень большая.

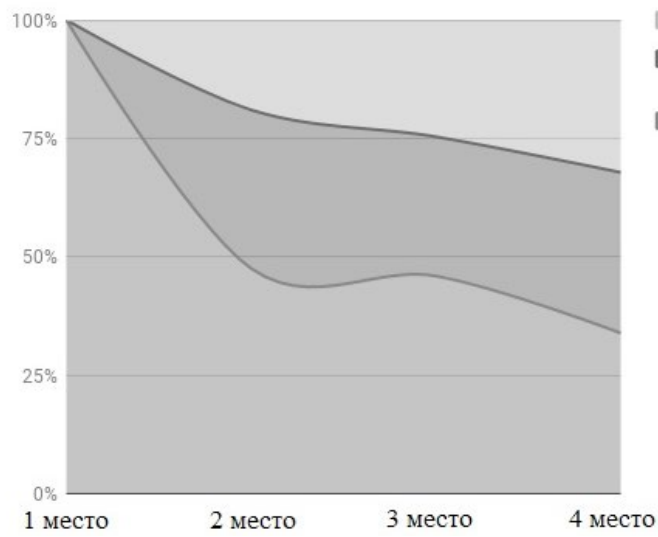

Поменяли город

Остались в городе, но поменяли вуз

- Остались в том же вузе и городе

Рис. 4. Структура паттернов мобильности у тех, кто указал до четырех вузов $(N=1864)$

Среди тех, кто указал не менее четырех мест образования (см. рис. 4), паттерны мобильности оказались следующими: $25 \%$ поменяли город образования, еще $25 \%$ - поменяли вуз, но не поменяли город, и около $50 \%$ продолжили учиться в том же городе и в том же вузе.

Эти данные подтверждают тезис об иммобильности инженеров. Вспомним еще раз отмеченную в исследовательской литературе тенденцию: молодые инженеры выбирают стабильность и стремятся к карьерному пути внутри одной, чаще всего крупной государственной организации[Козина, Виноградова, 2016]. 
Таким образом, судя по данным «ВКонтакте», профессия инженеров сегодня носит довольно седиментарный характер: люди по большей части продолжают учиться в том же вузе, где начали, и остаются жить и работать в том же городе, где учились. Иммобильность, на наш взгляд, создает издержки для развития инновационной экономики, поскольку талантливые кадры, по тем или иным причинам не пользующиеся образовательной или географической мобильностью, не имеют достаточно возможностей, чтобы проявить себя.

\section{Гендерные различия инженеров в образовании и на рабочем месте}

Мы уже отмечали выше (см. рис. 1), что женщин-инженеров как в образовании, так и в профессии в целом меньше, чем мужчин. Это согласуется с данными статистики и выводами исследователей.

Помимо этого, данные "ВКонтакте" показывают, что в образовательной карьере у женщин наблюдается нисходящий тренд (см. диаграмму на рисунке 5): чем выше образовательная ступень, тем меньше на ней женщин. Среди докторов наук, например, доля женщин около $10 \%$. Это схоже с тем, что Э. Блоссер писала о пролонгированном действии стереотипов в процессе образования - женщины "Выталкиваются" за пределы образовательной инженерной среды [Blosser, 2017].

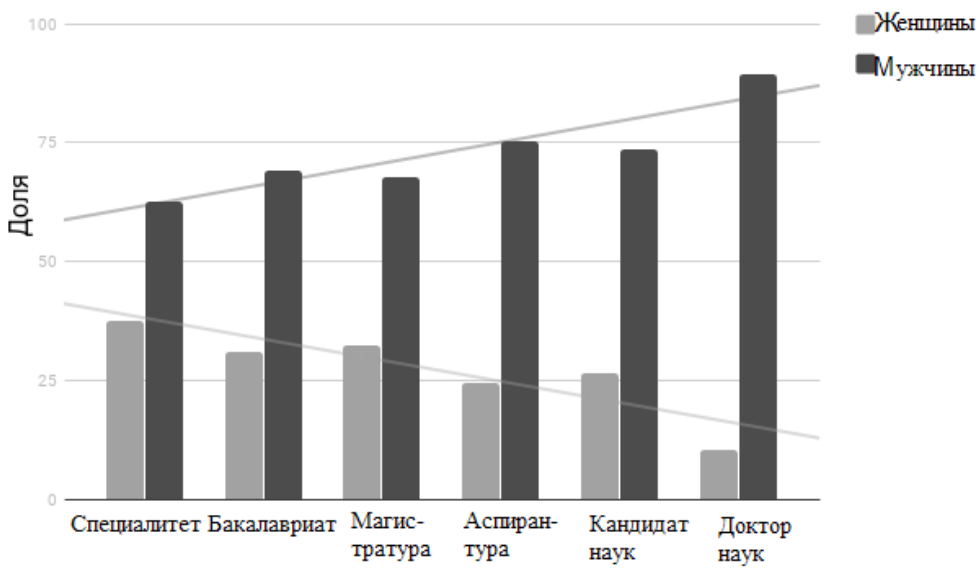

Рис. 5. Нисходящий тренд присутствия женщин на разных ступенях инженерной образовательной карьеры

Н. Ковалева [Kovaleva, 1999] указывает, что в 1990-х годах доля женщин в инженерной аспирантуре в России (технические науки) была на уровне $20 \%$, а в докторантуре - 30\%. По первому показателю (аспирантура) наши данные близки. Вероятно, факторы, воздействующие на соответствующий выбор и возможности женщин, остаются примерно теми же, что и в 1990-е годы. А вот с докторантурой, судя по нашей выборке, картина противоположная: на нее приходится только $10 \%$ женщин.

Мы также сделали частотное распределение названий должностей, которые пользователи "ВКонтакте» указывали в соответствующем разделе на сайте, ис- 
ходя из того, занимаются ими мужчины или женщины. Также мы выделили из них "самые женские" и "гендерно нейтральные" ${ }^{14}$ (см. рис. 6 и 7).

Выборка показала, что такие специальности, как микробиолог, химик, экономист, эколог, картограф, являются почти исключительно "женскими" (биологическая, химическая и экологическая специфика женщин-инженеров отмечались в литературе [Kovaleva, 1999]).

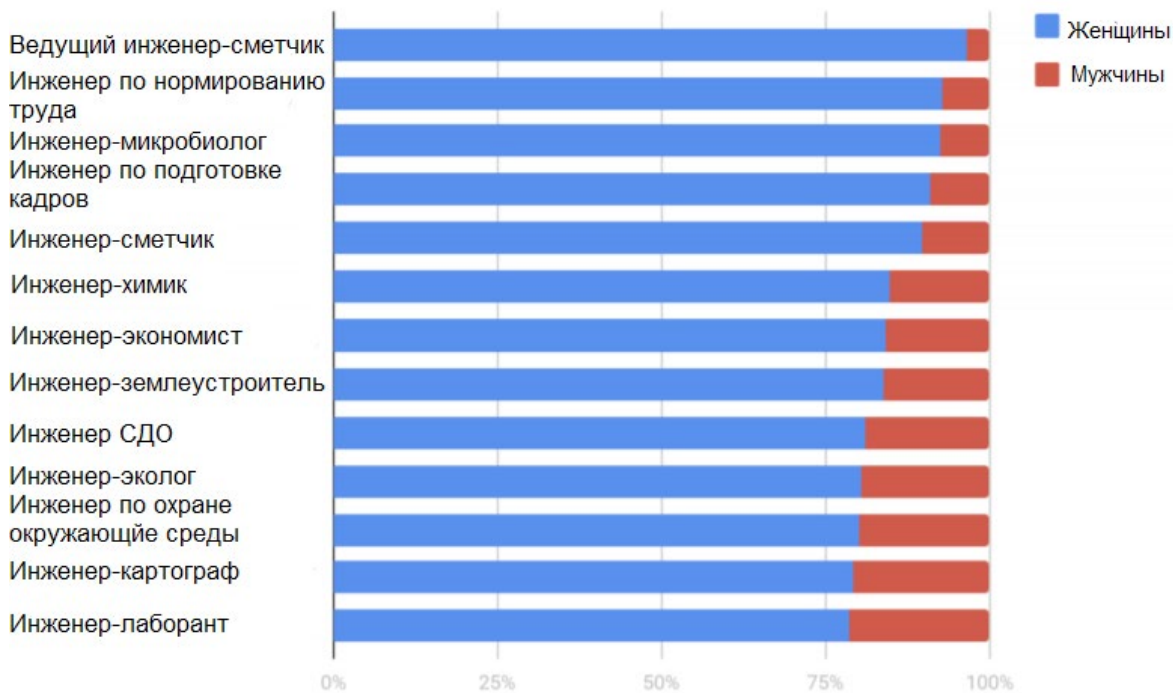

Рис. 6. Самые распространенные инженерные должности с высокой долей женщин

Женщины в основном работают сметчицами, нормировщицами труда, кадровиками, лаборантами. Это вписывается в наблюдение Р. Абрамова, что данная тенденция, появившаяся в позднесоветское время, все еще характерна для инженерной профессии в России [Абрамов, 2016].

Данная тенденция соответствует идее дуализма инженерной профессии, которую высказала исследовательница У. Фолкнер: все "технически сложные" инженерные работы остаются за мужчинами ${ }^{15}$ [Faulkner, 2020].

Среди «гендерно нейтральных" (см. диаграмму на рисунке 7) и при этом содержательных инженерных должностей - геолог и метролог. Согласно данным образовательной статистики процент геологов среди женщин - 36,9\%, картографов - 44\% ${ }^{16}$. Вероятно, причина этого - традиционное разделение геологических должностей и работ на «полевые» (делаются мужчинами) и «десктопные» (делаются женщинами). Это подтверждается тем, что доля женщин среди картографов - более $75 \%$.

\footnotetext{
14 Чтобы сэкономить место, мы не будем приводить отдельно диаграммы “мужских" инженерных специальностей и должностей, однако отметим, что среди них наиболее популярные должности - это инженер по бурению, по наладке и испытаниям, инженер-электроник, механик, сервисный инженер, инженер по эксплуатации.

15 Фолкнер также говорит то же самое о математике, но эту тенденцию в данных мы не увидели.

${ }^{16}$ Статистика: Высшее образование // Министерство высшего образования и науки РФ. 2020. URL: https://minobrnauki. gov.ru/action/stat/highed/ (дата обращения: 28.06.2021).
} 
Инженер ОТК

Инженер третьей категории

Инженер-геолог

Инженер ОМтC

Инженер-технолог

Инженер по тестированию

Инженер по метрологии

Инженер производственнотехнического отдела

Инженер-тестировщик

Инженер-технолог первой

категории

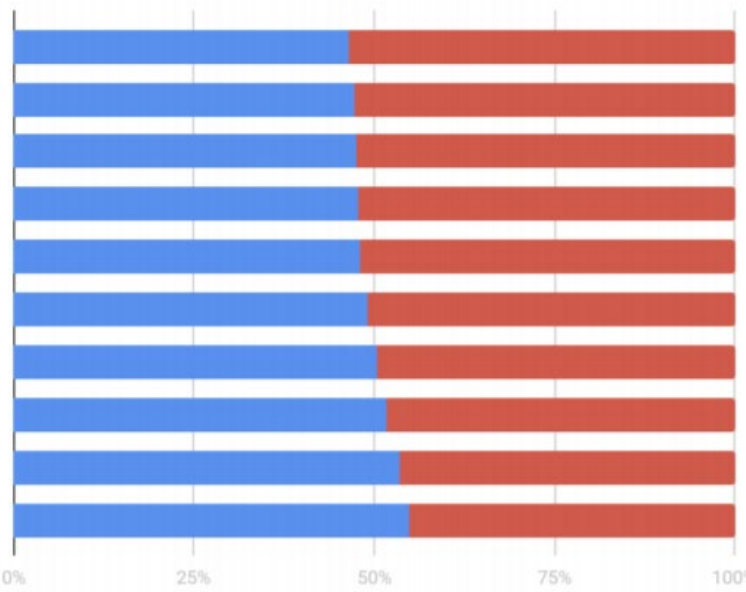

Рис. 7. «Гендерно нейтральные» инженерные должности

Остальные типы должностей связаны скорее с "формальными характеристиками» (оценка качества, материальное снабжение, тестирование и т.д.). На наш взгляд, этот гендерно нейтральный набор свидетельствует о равных долях мужчин и женщин в гибридных должностях, где необходимо и бюрократическое, и техническое знание. Заметим при этом, что упомянутые должности в основном носят вторичный характер и имеют, как правило, более низкий статус внутри организаций [Земнухова, 2020].

В целом наши данные подтверждают два момента, которые до того были уже озвучены в литературе. Женщины недопредставлены в инженерном образовании, где их доля в среднем - 25\%. Они имеют нисходящий тренд внутри образовательного трека, где только около $20 \%$ женщин имеют кандидатскую степень в инженерных науках и около $10 \%$ - докторскую. В отношении инженерных должностей подтверждается наблюдение Р. Абрамова: женщины в основном занимаются решением бюрократических задач, исключение составляют геологи, химики, микробиологи и экологи. В то же время тезис о маскулинности как ценности профессиональной культуры инженеров в нашей выборке подтверждения не получил, поскольку ряд технических должностей (материальное снабжение, тестирование, оценка качества) занимают одинаковые доли мужчин и женщин.

\section{Вывод}

Проанализировав 36 тысяч профилей инженеров в социальной сети «ВКонтакте", мы отметили следующее.

Во-первых, мода "инженерного возраста" по нашей выборке приходится на 33-35 лет. С одной стороны, это может быть последствием возрастного перекоса сети "ВКонтакте», но с другой - свидетельство того, что недостатка в инженерах для современной экономики нет.

Во-вторых, в профессионально активном возрасте мужчин-инженеров как минимум вдвое больше, чем женщин. Количественный рост числа мужчин в профессии начинается в районе 22 лет и продолжается до 40 лет. 
В-третьих, очевиден нисходящий образовательный тренд для женщин: чем выше ступень образования, тем меньше женщин на ней остается (доля женщин среди кандидатов наук - $20 \%$, среди докторов наук-10\%).

В-четвертых, на рабочем месте присутствует "дуализм" (термин У. Фолкнер). Женщины-инженеры зачастую занимают подчиненные должности и не включаются напрямую в решение технических задач, в то время как мужчины, наоборот, концентрируются на "технических должностях" (наладка, испытание, эксплуатация). Исключение составляют микробиологи, экологи, химики, картографы, геологи, метрологи, где преобладают женщины.

B-пятых, подавляющее большинство инженеров (86\%) иммобильны: они остаются жить и работать в городе, где получили первое образование. Остальных привлекают в первую очередь столицы - Москва и Санкт-Петербург.

В-шестых, несмотря на общую иммобильность инженеров, существуют города, притягательные для них с образовательной (Москва, Нижний Новгород, Воронеж) и профессиональной (Челябинск, Уфа) точки зрения, и, наоборот, те, которые отталкивают в образовательном (Самара, Челябинск) и профессиональном смысле (Пермь, Омск).

Поскольку данные были взяты из социальной сети "ВКонтакте», у них есть ряд ограничений. Они нерепрезентативны в статистическом смысле. Профессия «инженер" - это самоназвание. Сведения о себе заполняли сами пользователи, что ставит вопрос о том, насколько они были введены честно и достоверно, однако мы исходили из того, что "ВКонтакте" - это социальная сеть и в ней есть определенный публичный контроль, так что вероятность того, что пользователи будут намеренно сообщать ложные факты о себе, не слишком высока.

Несмотря на все ограничения, наши данные в целом совпадают с выводами о ге́ндерных и мобильных различиях в инженерных специальностях, встречающихся в литературе, а также с образовательной статистикой Министерства науки и высшего образования. Это триангулирует материалы и делает их более достоверными.

\section{Список литературы (References)}

Абрамов Р.Н. Профессиональная культура российских инженерно-технических специалистов: универсальные элементы // Социологические исследования. 2016. № 9. С. $96-104$.

Abramov R. N. (2016) Professional Culture of Russian Engineering and Technical Specialists: Universal Elements. Sociological Studies. No. 9. P. 96-104. (In Russ.)

Варшавская Е.Я., Котырло Е. С. Выпускники инженерно-технических и экономических специальностей: между спросом и предложением // Вопросы образования. 2019. № 2. С. 98-128.

Varshavskaya E. Ya., Kotyrlo E.S. (2019) Graduates of Engineering and Technical and Economic Specialties: Between Supply and Demand. Education Issues. No. 2. P. 98-128. (In Russ.) 
Земнухова Л. и др. Противоречия тестирования и социотехнические условия разработки в области информационных технологий // Приключения технологий. Барьеры цифровизации в России. СПб.: ФНИСЦ РАН. 2020. С. 71-95.

Zemnukhova L. et al. (2020) Testing Contradictions and Socio-Technical Conditions for Development in the Field of Information Technology. In: Adventure Technologies. Barriers to Digitalization in Russia. St. Petersburg: FCTAS RAS. P. 71-95. (In Russ.)

Козина И. М., Виноградова Е. В. Молодые инженеры: трудовые ценности и профессиональная идентичность // Мониторинг общественного мнения: Экономические и социальные перемены. 2016. № 1. С. 215-230.

Kozina I. M., Vinogradova E. V. (2016) Young Engineers: Work Values and Professional Identity. Monitoring of Public Opinion: Economic and Social Changes. No. 1. P. 215230. (In Russ.)

Колесникова Е. М. Инженерные династии и перспективы профессиональной биографии студентов инженерных вузов // Социологический журнал. 2018. № . 1. с. $55-72$.

Kolesnikova E. M. (2018) Engineering Dynasties and Prospects of Engineering Universities Students Professional Biography. Sociological Journal. No. 1. P. 55-72. (In Russ.)

Мансуров В.А., Юрченко О.В. Социальные установки и статус женщин инженеров в России в переходный период // Социология и общество: социальное неравенство и социальная справедливость (Екатеринбург, 19-21 октября 2016 года): Материалы V Всероссийского социологического конгресса / отв. ред. В.А. Мансуров. М.: Российское общество социологов. 2016. С. 9278-9286.

Mansurov V.A., Yurchenko O.V. (2016) Social Attitudes and Status of Women Engineers in Russia during the Transition Period. In: Mansurov V. A. (ed.) Sociology and Society: Social Inequality and Social Justice (Yekaterinburg, 19-21 October 2016): Materials of the V All-Russian Sociological Congress. Moscow: Russian Society of Sociologists. P. 9278-9286. (In Russ.)

Blosser E. (2017) Gender Segregation across Engineering Majors: How Engineering Professors Understand Women's Underrepresentation in Undergraduate Engineering. Engineering Studies. Vol. 9. No. 1. P. 24-44. https://doi.org/10.1080/19378629. 2017.1311902.

Faulkner W. (2020) Dualism, Hierarchies and Gender in Engineering. Social Studies of Science. Vol. 30. No. 5. P. 759-792.

Herrera L., Muñoz-Doyague M. F., Nieto M. (2010) Mobility of Public Researchers, Scientific Knowledge Transfer, and the Firm's Innovation Process. Journal of Business Research. Vol. 63. No. 5. P. 510-518. https://doi.org/10.1016/j. jbusres.2009.04.010.

Kaiser U., Kongsted H. C., Rønde T. (2015) Does the Mobility of R\&D Labor Increase Innovation? Journal of Economic Behavior \& Organization. Vol. 110. P. 91-105. https://doi.org/10.1016/j.jebo.2014.12.012. 
Kovaleva N. (1999) Women and Engineering Training in Russia. European Journal of Education. Vol. 34. No. 4. P. 425-435.

Sagebiel F., Dahmen J. (2006) Masculinities in organizational cultures in engineering education in Europe: results of the European Union project WomEng. European Journal of Engineering Education. Vol. 31. No. 1. P. 5-14. https:// doi.org/10.1080/03043790500429922.

Slaton A. (2015) Meritocracy, Technocracy, Democracy: Understandings of Racial and Gender Equity in American Engineering Education. In: Christensen S. H., Didier C., Jamison A. et al. (eds.) International Perspectives on Engineering Education. Vol. 1: Engineering Education and Practice in Context. Springer. P. 171-189. https:// doi.org/10.1007/978-3-319-16169-3_8. 